\title{
Combined thoracoabdominal aortic repair and coronary artery bypass grafting in a patient with impaired left ventricular function
}

\author{
Homare Okamura, MD, PhD, Atsushi Miyagawa, MD, Yuichiro Kitada, MD, and \\ Mamoru Arakawa, MD, PhD, Tokyo, Japan
}

\author{
From the Department of Cardiovascular Surgery, Nerima Hikarigaoka Hospital, Tokyo, Japan. \\ Disclosures: Authors have nothing to disclose with regard to commercial support. \\ Received for publication Jan 30, 2019; revisions received Feb 24, 2019; accepted for publication March 7, 2019; \\ available ahead of print April 13, 2019. \\ Address for reprints: Homare Okamura, MD, PhD, 2-11-1 Hikarigaoka, Nerima-Ku, Tokyo 179-0072, Japan \\ (E-mail: homareo@jadecom.jp). \\ J Thorac Cardiovasc Surg 2019;158:e35-7 \\ $0022-5223 / \$ 36.00$ \\ Copyright (C) 2019 by The American Association for Thoracic Surgery \\ https://doi.org/10.1016/j.jtcvs.2019.03.018
}

- Video clip is available online.

In patients with aortic aneurysm and coronary artery disease (CAD), the sequence of treatments remains controversial. Herein, we report a case of simultaneous repair of a thoracoabdominal aortic aneurysm (TAAA) and coronary artery bypass grafting (CABG) in a patient with impaired left ventricular (LV) function.

\section{CASE}

A 77-year-old man who presented with weakness was transferred to our institution. His comorbidities included hypertension and emphysema. Transthoracic echocardiography revealed an LV ejection fraction of $20 \%$ and LV end-diastolic dimension of $70 \mathrm{~mm}$. Coronary angiography revealed that the left anterior descending artery was occluded (Figure 1, $A$ ). He was diagnosed with heart failure due to coronary ischemia. Computed tomography scan revealed the extent III TAAA extending from the descending aorta at T10 to the origin of the superior mesenteric artery with a maximal diameter of $70 \mathrm{~mm}$ (Figure 1, B). The occluded left descending artery was considered anatomically unsuitable for percutaneous intervention. After medical treatment, we planned to simultaneously perform the TAAA repair and CABG.

The operation was performed with the patient in the right lateral oblique position. Lumbar cerebrospinal fluid drainage was not used. The chest was accessed through the seventh intercostal space. The great saphenous vein was harvested. A partial femorofemoral bypass was

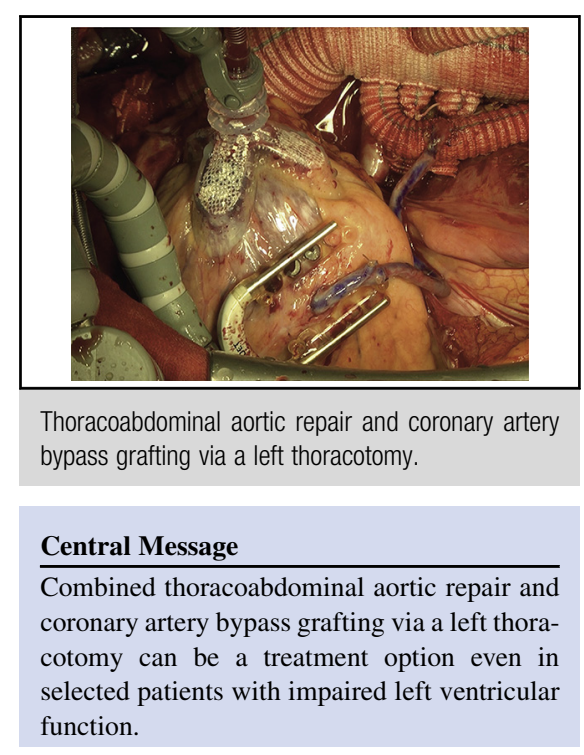

initiated to provide distal perfusion during aortic crossclamping and hemodynamically support during $\mathrm{CABG}$ with the heart beating. Mild hypothermia $\left(34^{\circ} \mathrm{C}\right)$ was applied. The cardiopulmonary bypass (CPB) flow was adjusted to approximately $2.0 \mathrm{~L} / \mathrm{min}$. After crossclamping the descending and abdominal aorta, proximal and subsequent distal anastomoses were performed with a 28-mm 4-branched Dacron tube graft (J graft Japan; Lifeline, Tokyo, Japan). Selective antegrade perfusion into the celiac and superior mesenteric arteries was performed. Saphenous vein graft was anastomosed to the branch of the tube graft. Subsequently, the celiac artery was reconstructed. After the pericardium was opened, the left anterior descending artery was well exposed by pulling the heart to the left using a Starfish heart positioner (Medtronic Inc, Minneapolis, Minn; Figure 2, $A$ and $B$; Video 1). Finally, the saphenous vein graft was anastomosed to the left anterior descending artery during $\mathrm{CPB}$ with the heart beating (Figure 2, $C$ ). The CPB time was 168 minutes, 30 minutes of which was for $\mathrm{CABG}$.

The postoperative course was uneventful. Postoperative pain management included an intravenous fentanyl infusion for 2 days and oral acetaminophen thereafter. The duration of stay in the intensive care unit and hospital was 4 and 


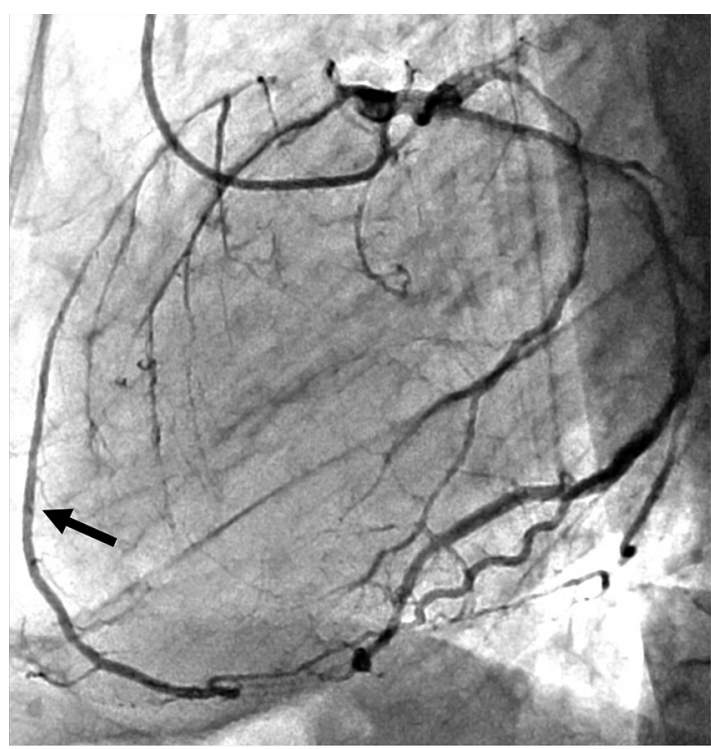

A

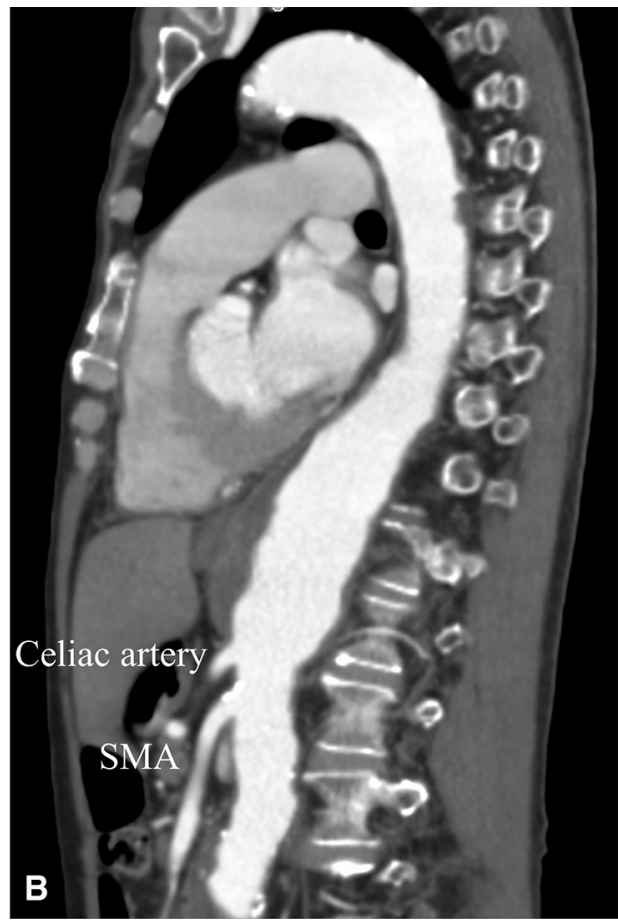

FIGURE 1. Preoperative coronary angiography and computed tomography. A, Coronary angiography of the left coronary artery. The arrow indicates the left anterior descending artery. B, Contrast-enhanced computed tomography scan. SMA, Superior mesenteric artery.

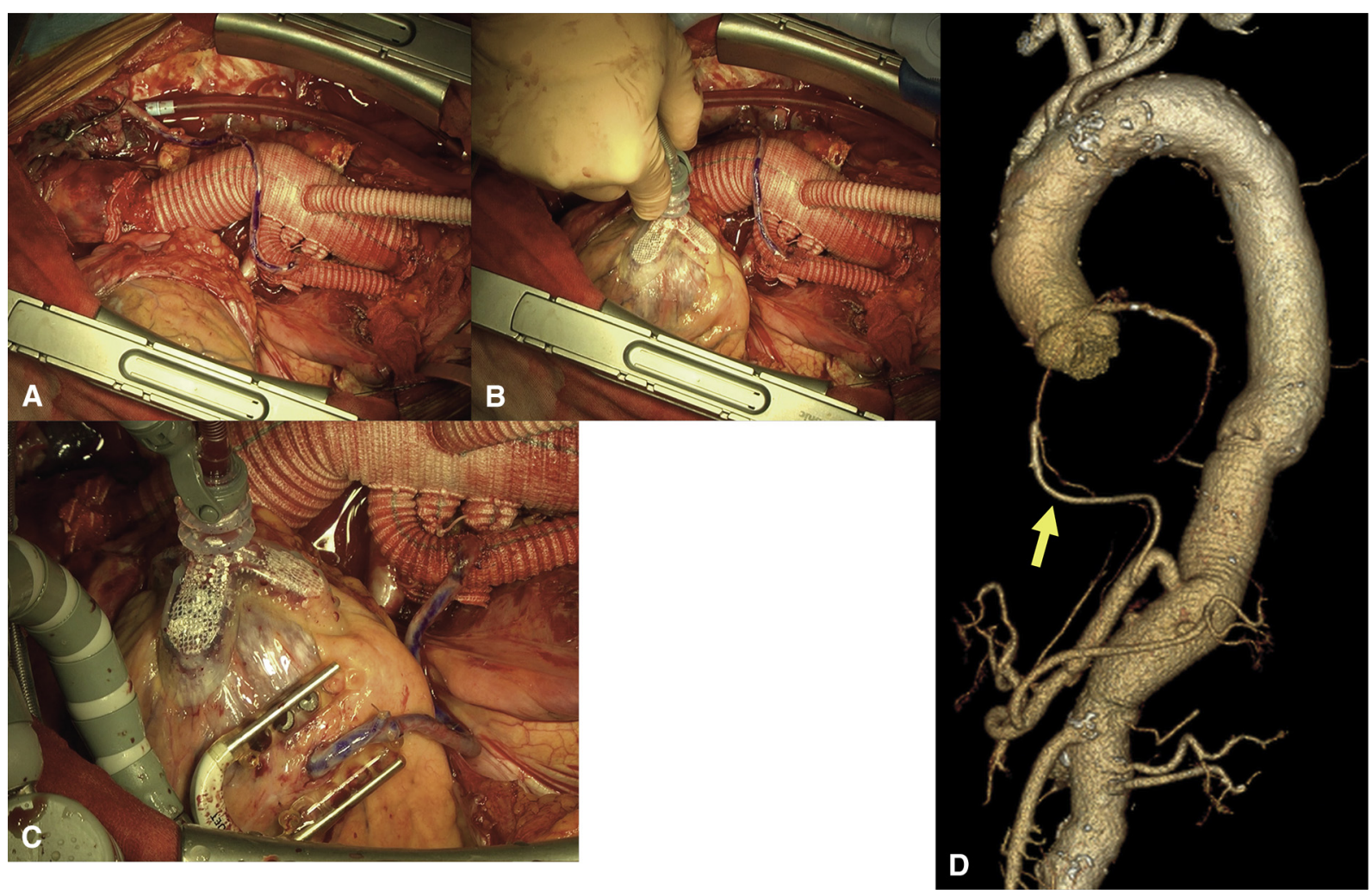

FIGURE 2. A-C, Intraoperative view. A, Exposure of the heart via left thoracotomy. B, The left anterior descending artery was well exposed by pulling the heart to the left using a heart positioner. C, Coronary artery bypass grafting to the left anterior descending artery using a saphenous vein graft. D, Postoperative 3-dimensional computed tomography scan. The arrow indicates the saphenous vein graft. 


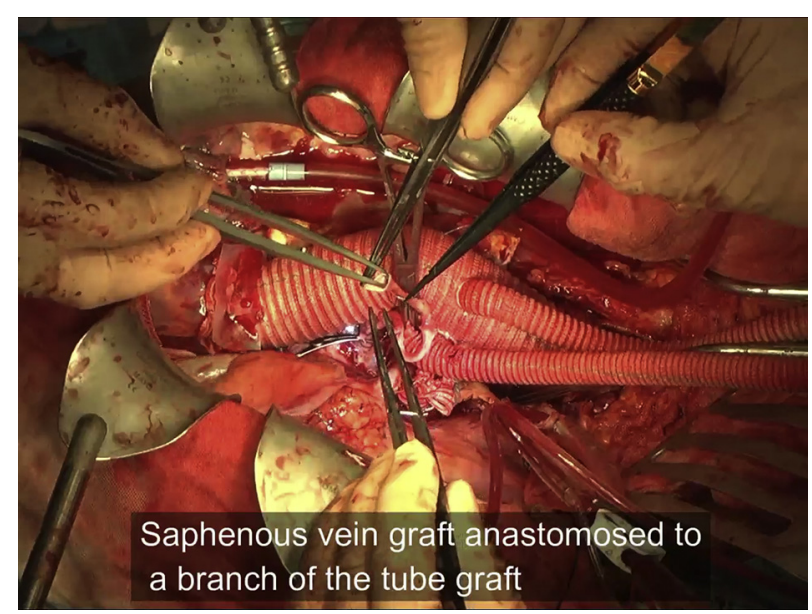

VIDEO 1. Preoperative examinations and an intraoperative video that shows the concomitant coronary artery bypass grafting via a left thoracotomy. Video available at: https://www.jtcvs.org/article/S0022-5223(19) 30688-9/fulltext.

21 days, respectively. Postoperative computed tomography imaging showed a patent saphenous vein graft and satisfactory repair of the TAAA (Figure $2, D$ ). He is doing well according to the 2-month follow-up findings. Follow-up echocardiography showed an LV ejection fraction of $20 \%$.

\section{DISCUSSION}

In TAAA repair, the treatment for an underlying significant CAD is controversial. When coronary revascularization precedes the elective aortic repair, it carries the risk of the aneurysm rupture in the interval before the aortic repair. The probability of aneurysmal rupture within 1 year was approximately $60 \%$ in our patient. ${ }^{1}$ Precedent percutaneous coronary intervention can also increase the risk of bleeding associated with antiplatelet therapy and stent thrombosis in aortic repair. On the contrary, Girardi and colleagues showed that preoperative coronary intervention was safe in patients who underwent TAAA repair. ${ }^{2}$ When aortic repair is performed before coronary revascularization, perioperative myocardial infarction is a concern.
The presence of CAD was shown to be associated with the perioperative mortality of aortic repair. ${ }^{3}$ From that point of view, combined TAAA repair and coronary revascularization is desirable.

In our technique, CABG on the heart beating does not require cross-clamping, delivery of cardioplegia, or hypothermic circulatory arrest. The use of partial bypass and a heart positioner enables simultaneous coronary revascularization through left thoracotomy, even in patients with a reduced LV ejection fraction. Care should be taken in partial femorofemoral bypass to ensure appropriate perfusion of the upper and lower body. Considering the advanced age and reduced LV function, we simultaneously harvested a saphenous vein graft instead of the left internal mammary artery while opening the chest to shorten the operation time. If needed, it is possible to perform CABG using the left internal mammary artery via a median sternotomy in the future.

Several authors have reported a combined procedure of TAAA repair and CABG via left thoracotomy through the fifth intercostal space in patients with a normal LV function. ${ }^{4,5}$ In our patient, the use of a heart positioner provided a good exposure of the heart via the seventh intercostal space.

In conclusion, concomitant CABG along with TAAA repair can be a therapeutic alternative and provides advantages over a 2 -staged operation in selected patients.

\section{References}

1. Juvonen T, Ergin MA, Galla JD, Lansman SL, Nguyen KH, McCullough JN, et al Prospective study of the natural history of thoracic aortic aneurysms. Ann Thorac Surg. 1997;63:1533-45.

2. Girardi LN, Rabotnikov Y, Avgerinos DV. Preoperative percutaneous coronary intervention in patients undergoing open thoracoabdominal and descending thoracic aneurysm repair. J Thorac Cardiovasc Surg. 2014;147:163-8.

3. Hirose K, Chikamori T, Hida S, Tanaka H, Igarashi Y, Watanabe Y, et al. Prevalence of coronary heart disease in patients with aortic aneurysm and/or peripheral artery disease. Am J Cardiol. 2009;103:1215-20.

4. Mihaljevic T, Tönz M, von Segesser LK, Turina MI. Combined coronary artery bypass grafting and repair of aneurysm of the descending aorta. Ann Thorac Surg. 1999;67:1497-9.

5. Attaran S, Field M, Kuduvalli M, Oo A. A combined procedure of thoracoabdominal aortic aneurysm repair and coronary artery bypass grafting: report of two cases. J Thorac Cardiovasc Surg. 2011;141:1078-9. 